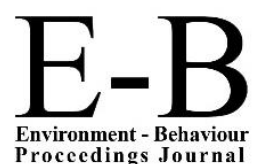

Environment - Behaviour
Procecdings Journal

\section{CSSR 2017}

https://www.amerabra.org; https://fspu.uitm.edu.my/cebs; https://www.emasemasresources.com

$4^{\text {th }}$ International Conference on Science \& Social Research

The Pines, Malacca, Malaysia, 06 -07 December 2017

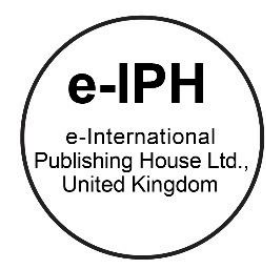

\title{
A Comparative Study on the Implementation of Corporate Integrity between Malaysian Public and Private Sectors Organization
}

\author{
Rafidah Zainal', Ayub Md. Som ${ }^{1,2}$, Nafsiah Mohamed ${ }^{1}$ \\ ${ }^{1}$ Accounting Research Institute, ${ }^{2}$ Faculty of Chemical Engineering \\ Universiti Teknologi MARA, Shah Alam, Selangor, Malaysia \\ rafidahbintizainal@gmail.com, ayub522@uitm.edu.my,nafsiah793@uitm.edu.my \\ Tel: 0148174563
}

\begin{abstract}
With regards to fighting corruption and promoting transparency in organization, agency integrity unit was established in 2013 in managing issues related to integrity. In addition, a Corporate Integrity Assessment Questionnaire (CIAQ) has been developed by the Malaysian Institute of Integrity in collaboration with several Malaysian academicians to measure the implementation of the integrity system in their organization. There were 173 respondents from Company A (public sector), and 220 respondents from Company B (private sector) and the findings showed that Company A has integrity level between $75 \%$ to $100 \%$. In contrast, Company B integrity level is between $50 \%$ to $75 \%$.
\end{abstract}

Keywords: corporate integrity, public sector, private sector, statutory body,

eISSN: 2398-4287 @ 2020. The Authors. Published for AMER ABRA cE-Bs by e-International Publishing House, Ltd., UK. This is an open access article under the CC BYNC-ND license (http://creativecommons.org/licenses/by-nc-nd/4.0/). Peer-review under responsibility of AMER (Association of Malaysian Environment-Behaviour Researchers), ABRA (Association of Behavioural Researchers on Asians) and cE-Bs (Centre for Environment-Behaviour Studies), Faculty of Architecture, Planning \& Surveying, Universiti Teknologi MARA, Malaysia.

DOI: https://doi.org/10.21834/ebpj.v5iSI1.2329

\subsection{Introduction}

In line with Malaysia's vision, i.e. Vision 2020, one of the key challenges identified in achieving high-income status is corruption. To fight corruption, the government has introduced the National Integrity plan intending to reduce private and public sector corruption. Until 2016, there are almost 887 integrity units in all public sector organizations of Malaysia. Chief Integrity Unit (CIU) has been introduced as a control mechanism in the governance to fight corruption. CIU plays a crucial role in shaping ethics and integrity culture in an organization (Ismail, Haron, \& Sajari, 2016).

According to Transparency International (TI) based in Germany, the Corruption Perception Index for Malaysia is currently at 47/100, which is ranked 61 in the world. Not only that, seeing how the government together with private sector in promoting integrity shows that the implementation of integrity in workplace is important. Since the introduction of Corporate Integrity Pledge (CIP), 1,119 organization have signed the pledge. Therefore, this paper study the comparison of the implementation of corporate integrity in public and private sector in Malaysia.

\subsection{Literature Review}

Role of Certified Integrity officer (CelO) includes coordinating and monitoring integrity programs, reporting on any breach on integrity, implementing a recovery program of integrity, advising management in term of integrity, and ensuring compliance to directives/regulations of organization. Ismail et al., (2016) showed that level of ethics and integrity for their case studies was more than $50 \%$ which indicated that CIU was a severe starting point to embark on proper integrity mechanism into their workplace.

eISSN: 2398-4287 @ 2020. The Authors. Published for AMER ABRA cE-Bs by e-International Publishing House, Ltd., UK. This is an open access article under the CC BYNC-ND license (http://creativecommons.org/licenses/by-nc-nd/4.0/). Peer-review under responsibility of AMER (Association of Malaysian Environment-Behaviour Researchers), ABRA (Association of Behavioural Researchers on Asians) and cE-Bs (Centre for Environment-Behaviour Studies), Faculty of Architecture, Planning \& Surveying, Universiti Teknologi MARA, Malaysia. DOI: https://doi.org/10.21834/ebpj.v5iSI1.2329 
The statutory body can be considered as part of public services as they resemble in many aspects due to adoption of the same procedures of Public Service relating to appointments, terms and condition of services, and the compensation system. However, with the implementation of separation concept under the New Remuneration System that has become effective since 1st January 1993 , several public sector agencies have been given the freedom to institute their policies and procedures. These agencies, whose activities are akin to that of business and have a good financial stand, are allowed to decide or make their policies and procedures on appointments, terms and conditions of services (Abd Rauf et al., 2009).

The statutory body can also define as a corporate body that is incorporated according to the provisions of Federal Law. It is a public authority (an agency from the Government of Malaysia), but it does not include a local or corporate body which is incorporated under the New Companies Act 2016. Although it is the same as a company, it is a separate entity which has the power to administer, sue and be sued on its name, sign contracts, private, buy and hold assets (Said, Omar, Zakaria, \& Yahya, 2015).

The private industry is a business organization that is owned and run by private individuals. There are various types of business in the private industry, for instance; Sole Proprietor, Partnership, Limited Companies, Cooperatives, Franchise, and Charities. The main goal of these organizations is to earn profit and increase their market's shares (Teacher, 2017). Berhad (Bhd) is one of the public limited companies whose shares can be offered to the public for fixed periods and any other forms of subscription. The minimum number of shareholders is two with an unlimited number of members. Their financial reporting has to be disclosed publicly with higher standards. Their financial information will also be available for the public. Lastly, the public can subscribe to shares of public companies whereas public individuals can only own shares in a private limited company through a shareholder's agreement with the approval from existing shareholders (Khoo, 2017).

Corporate Integrity Assessment Questionnaire (CIAQ) was developed by Malaysian Institute of Integrity (INTEGRITI) in 2010 along with few Malaysian academicians as a tool to measure integrity implementation in an organization. The integrity level in an organization has been assessed by using a set of questionnaire consists of 12 Dimensions. Dimension One is about Vision and Goals, which focus on to identify whether the organization has identified and defined its core ethical values or principles, and has integrated those values into everyday business. Dimension Two is on the Leadership, which measures the responsibility of the organizations to lead in shaping, guiding, and supporting ethics and integrity plan. The Third Dimension is on Infrastructure, that will explore the way the organization establishes or structures their ethics and integrity function to achieve their goals (Sajari, Haron, \& Ismail, 2016).

Dimension Four which is on Legal Compliance, Policies and Rules will assess on the internal framework that provides the stage for ethical behaviour which includes compliance with the external legal framework within the organizational operation such as core laws, policies, rules and guidance. Dimension Five is on Organizational Culture, which stresses on the overall organizational culture and implementation of ethical conduct in the context of their mission, vision, structure, and strategy. Dimension Six (Disciplinary and Reward Measures) is about how the organization sets and administers its standards for its ethical conduct and behaviour in line with integrity (Said \& Omar, 2014).

Dimension Seven is on Measurement, Research and Assessment which evaluate on how ethics and integrity are measured, whether the organization has undertaken research to support and create a culture of ethics and integrity as well as their assessment processes around ethics, integrity, and organizational culture. Dimension Eight (Confidential Advice and Support) describes whether the organization has confidential, neutral, professional and independent ethics advice to all employees and other stakeholders. Dimension Nine which is on Ethics training and Education, will measure the organization ethics and integrity awareness, training and education, and also the combination of such training into the overall development of all employees. This also includes the establishment of ethicsrelated training and skill-building throughout the life cycle of employees, and the degree to which these initiatives were integrated into organization training commitments (Companies Commission of Malaysia, 2005).

Dimension Ten is on Ethics Communication that describes how ethics and integrity plans were expressed and promoted, both internally and externally. It also shows how an organization defines its stakeholders and how it gears its vital message to distinct audiences. Dimension Eleven is about Whistle Blowing, which explores how organization encourages individuals to speak up and make reports of unethical action, both internal and external to the entity. It also explores the methods and protections provided for employees who wish to make their organization aware of any possible misconduct or any illegal actions. Dimension 12 is the last dimension which is on Accountability. Accountability is a mechanism that was offered to ensure that the organization and its employees perform their duties faithfully towards the citizens and other stakeholders. It also operates by specifying the relationship between public officials' behaviour and performance on the one hand, and rewards and punishments on the other (Ismail et al., 2016).

All these dimensions were then compared with a global Ethics and Integrity benchmark founded by Ellis Dubinsky known as Global Ethics and Integrity Benchmark (GEIB). GEIB is a benchmark that were grouped into five-level progress which namely $0 \%, 25 \%, 50 \%$, $75 \%$ and $100 \%$. $0 \%$ level remarks that the company does not have any intention to implement ethics and integrity. As for $25 \%$ is for symbolic action by the organization to introduce ethics and integrity, $50 \%$ for a start to partially implement ethics and integrity, $75 \%$ shows that the organization is going into a vigorous approach and lastly $100 \%$ for best practices in ethics and integrity in an organization (Sajari, Haron, \& Ismail, 2017).

For easy understanding and discussion, the statutory body (public sector) will be termed as Company A; whereas the private sector will be termed as Company $B$ throughout this study.

\subsection{Methodology}

This paper focuses on a quantitative study to assess the level of corporate integrity implementation stage between the public sector, i.e. statutory body and private sector using Corporate Integrity Assessment Questionnaire (CIAQ). By using the 12 Dimensions 
questionnaire previously developed by Malaysian Integrity Institute (INTEGRITI) and a few Malaysian university academicians, it reflects the level of integrity in the organization after being compared with GEIB. The questionnaires were distributed in a one-day session. This is to ensure all questionnaires obtain were completed and to avoid for missing data or irregularity.

The questionnaires consist of 214 items with the response scale of 5 -point scale. The scales used are from 0 to 4 . ' 0 ' will denote as not sure, ' 1 ' as strongly disagree, ' 2 ' as disagree, ' 3 ' as agree and ' 4 ' as strongly agree. To calculate the total score for each dimension, scales 1 and 2 are added together and denoted as "At least disagree" and scales 3 and 4 are added up and denoted as "At least agree", and lastly as for scale ' 0 ' it was ignored.

Cronbach's Alpha is used to conduct a reliability test to ensure that the questions in this study is correlated with one another. According to Taber, (2017), despite having followed a rule-of-thumb that alpha should reach 0.70 for an instrument to be acceptable, there was limited ground for adopting such heuristic. Besides, it ought to assume that a very high value of alpha was not always a good thing because it may indicate an inefficient level of redundancy in items.

As for this study, the Cronbach's Alpha ranged from 0.66 as the lowest and 0.95 as the highest. Based on these values, this study was considered as a high value consistency. Hence, it provides evidence that the measurement model possesses excellent measurement properties. As for the data obtained, it was analysed by using Microsoft Excel.

The limitations in this study are the time spent to collect all of the questionnaires. It is time consuming due to the availability of the respondents. Not only that, the possibility for respondents did not take seriously in answering the questions also come into the limitation in this study. This study uses only one company to represent each sector. Future research should compare more organizations from each sector.

\subsection{Results}

In total, 173 respondents from Company A and 220 respondents from Company B took part in this assessment by returning fully completed questionnaires. Company A respondents are from various branches in various departments. 87 of them are male, and 86 are female. The respondents from Company B are from top management (6), managers (58), and executives (156).

Table 1. Overall company progress on implementation stages of the corporate integrity level

\begin{tabular}{|c|c|c|c|}
\hline No. & Dimensions & Company A (\%) & Company B (\%) \\
\hline 1. & Visions and Goals & 90 & 73 \\
\hline 2. & Leadership & 80 & 69 \\
\hline 3. & Infrastructure & 88 & 46 \\
\hline 4. & Legal Compliance, Policies and Rules & 89 & 69 \\
\hline 5. & Organizational Culture & 85 & 64 \\
\hline 6. & Disciplinary and Rewards Measures & 83 & 64 \\
\hline 7. & Measurement, Research, and Assessment & 73 & 46 \\
\hline 8. & Confidential Advice and Support & 67 & 55 \\
\hline 9. & Ethics and Training and Education & 60 & 50 \\
\hline 10. & Ethics Communication & 83 & 51 \\
\hline 11. & Whistleblowing & 67 & 56 \\
\hline \multirow[t]{2}{*}{12.} & Accountability / Corporate Social Responsibility & 76 & 73 \\
\hline & OVERALL & 78 & 60 \\
\hline
\end{tabular}

Table 1 shows the scores obtained by each company for each dimension. Both companies have demonstrated that their overall scores are above $50 \%$ which are $78 \%$ for Company A. In contrast, $60 \%$ for Company B. These indicate that they are beginning to start ethics and integrity mechanisms in their company to maintain highest levels of transparency, integrity and professionalism. These number also meant that $78 \%$ of respondents from Company $A$ at least agree that their company has a proper integrity system. As for the Company $\mathrm{B}$, their score is $60 \%$ which is slightly lower than Company $\mathrm{A}$.

Company A has obtained the highest score (90\%) in Dimension One, which is Vision and Mission. It is followed by Dimension Four (89\%) which is only one per cent lower than the highest score. Dimension Four is about the legal compliances, policies and rules applied by the company in implementing integrity program. In this dimension, it comprises the legal framework for the organization's ethics and integrity system, including the core laws, policies, rules and guidelines (Said \& Omar, 2014). These shows that Company A has already provided the laws, policies and rules, and it has been distributed among the employees.

The lowest score obtained by Company A is on Dimension Nine (Ethics, Training and Education) which, scored $60 \%$. Both Dimension Eight and Dimension Eleven earned 67\% agreement among the respondents. These show that the company is earnest in implementing ethical environment in the workplace. Hence, they need to provide more integrity training and evaluate it accordingly. As for Whistleblowing (Dimensions 11), the first step is to inform all employees that their organization provides "hotline" or "helpline" services as encouragement or support anonymous complaint on ethical behaviour.

As for Company B, they achieved $73 \%$ as their highest score. Though the score is lower than the other company, that is the highest score (73\%) obtained by Company B for Dimension One and also in Dimension 12 which is Corporate Social Responsibility (CSR). It means that Company $B$ has been focusing more on their CSR to invest in the communities and stakeholders with which their interactions, encompassing government relations, environmental consciousness, sustainability and community impact (Companies Commission of Malaysia, 2014).

The lowest score for Company B is $46 \%$. This score is between $25 \%$ to $50 \%$ which shows that Company B is moving in a good direction to implement ethics and integrity in their company. There are two dimensions which scores are at $46 \%$, namely; Infrastructure 
(Dimension 3) and Measurement, Research, and Assessment (Dimension 7). Compared to Company A, Company B is only one band lower than Company A. If Company B wants to step up their performance, for Dimension 3 , they can start by preparing integrity activities report and distribute it to employees and use designated budget for integrity activities effectively. Company B can improve their Dimension 7 by providing opportunities for employees to involve in activities regarding ethics and integrity.

\subsection{Discussion}

Based on the findings; Company A has shown much better performance compared to Company B. This might be due to early establishment of integrity culture in Company A as compared to Company B. The core issue for Company B performance are mainly the lack of dissemination of information related to policies or guidelines to their employees. These was shown in the analysis as more respondents answered not sure rather than agree or disagree. Besides that, the use of media platform and website were not fully maximized.

Merely changing the structure of organizations is not enough to improve their situation. Malaysian public and private sectors must transform into a reliable and efficient sector by ensuring good governance and its proper assessment system. Enhancing the practices of integrity system can help achieve the aspiration of stakeholders and ensure accountability in the public sector (Said, Alam, \& Khalid, 2016). Aziz et al., (2015) suggested that every department and ministry should produce or report their ethics and integrity activities that they have organized in order to cultivate the good governance in the organization. The report also should be available for public to assess to educate the public on the significant step that has been taken by the government in reducing misconduct among its employees. Though it was suggested to every department and ministry only, the same suggestions could be applied by private and public sectors to show their commitment and determination to show transparency in their organization.

Although the public sector was accused for being strict in carrying their daily activities and red taped procedural, the importance of implementing the internal control system cannot be desolate. The public sector is a guardian for the stakeholders who protected their interest by ensuring every people treated fairly and just to gain a harmonious nation (Aziz, Rahman, Alam, \& Said, 2015). Hence, the proper system and procedure that can protect the country must be set up and be in place. Besides, integrity among employees in an organization is essential to prevent employees from being involved in misconduct actions. Many studies agree that a high level of integrity among the leaders can help the organization to avoid any unethical behaviour among their employees (Bakri, Said, \& Karim, 2015).

\subsection{Conclusion}

Many pieces of research were carried out on integrity; however, this paper focuses on the comparison of the implementation stage of ethics and integrity in an organization to increase awareness on integrity. The reason why these two sectors were compared is due to the slightly different in organization structure. In a nutshell, Company A has integrity level between $75 \%$ to $100 \%$. This show that they already have a robust approach in setting ethics and integrity in the organization. As for Company B, they are in between $50 \%$ to $75 \%$. This shows that they are in the right direction to implement ethics and integrity in their organization. Ismail, et al., (2016), emphasizes that organizations need to be observe to have a high level of ethics and integrity by the public so that they are able to fulfil their responsibilities.

There are some limitations during this study conducted. Since the scale for this questionnaire uses seven-point Likert scale, there are times when respondents will be biased and lead them to their personal judgment. Besides that, the demographic section was still under development during this study. In future, the same demographic section should be use to analyse the result in more details. The findings can be useful in providing consciousness to the citizens to adopt good governance in anyways to ensure the integrity environment of the organizations (Rosli, Aziz, Mohd, \& Said, 2015). Thus, managing their integrity level is essential to analyse whether or not they are performing their best in fighting corruption.

For future research, a comparison of more organizations from each sector can be done. Besides that, analysis from integrity report can lessen the time for collecting data.

\section{Acknowledgments}

The authors wish to extend their gratitude to the Malaysian Ministry of Higher Education for financial support through 600-RMI/ARI_IRES $5 / 3$ (0053/2016). The authors would also like to thank the Accounting Research Institute (ARI) and Faculty of Chemical Engineering, Universiti Teknologi MARA (UiTM), Shah Alam for the supports given.

\section{References}

Abd Rauf, F., Yusoff, H., Yatim, N., Poobalan, U. R., Che Salleh, S., \& Othman, R. (2009). Components Of Public Sector. In Public Sector Accounting Malaysian Context (2nd ed., p. 5). Petaling Jaya: Pearson Malaysia Sdn. Bhd.

Aziz, M. A. A., Rahman, H. A., Alam, M. M., \& Said, J. (2015). Enhancement of the Accountability of Public Sectors through Integrity System, Internal Control System and Leadership Practices: A Review Study. Procedia Economics and Finance, 28(April), 163-169. https://doi.org/10.1016/S2212-5671(15)01096-5 
Bakri, H. H. M., Said, J., \& Karim, Z. A. (2015). Case Study on Integrity among Royal Malaysian Police (RMP): An Ethical Perspective. Procedia Economics and Finance, 28(April), 121-125. https://doi.org/10.1016/S2212-5671(15)01090-4

Companies Commission of Malaysia. (2005). Corporate Integrity. Corporate Responsibility Management, 1, 39.

Companies Commission of Malaysia. (2014). From Pledge to Practice: A Guide to Implement the Corporate Integrity System, 1-48.

Ismail, I., Haron, H., \& Sajari, A. (2016). A Case Study on the Role of Chief Integrity Unit (CIU) as a Control Mechanism in Malaysian Public Sector Organization. New Zealand Management Accounting Symposium 2016, 1-27.

Khoo, J. (2017). 4 Differences between Sendirian. Retrieved September 15, 2017, from http://dollarsandsense.my/4-differences-between-sendirian-berhad-and-berhad/

Rosli, M. H., Aziz, M. A. bin A., Mohd, F., \& Said, J. (2015). Integrity Systems in Malaysian Public Sector: An Empirical Finding. Procedia Economics and Finance, 28(October), 260-265. https://doi.org/10.1016/S2212-5671(15)01109-0

Said, J., Alam, M. M., \& Khalid, M. A. (2016). Relationship between good governance and integrity system. Humanomics, 32(2), 151-171. https://doi.org/10.1108/H-022016-0008

Said, J., \& Omar, N. (2014). Corporate Integrity System: Comparative Analysis of Two Giant Government Linked Companies. Procedia - Social and Behavioral Sciences, 145, 12-17. https://doi.org/10.1016/j.sbspro.2014.06.006

Said, J., Omar, N., Zakaria, N. B., \& Yahya, N. (2015). Corporate Integrity System Infrastructure : Empirical Findings from Statutory Body. International Conference on Islamic Economics, Governance and Social Enterprise, IConIGS 2015, (December).

Sajari, A., Haron, H., \& Ismail, I. (2016). Role of Chief Integrity Officer in Malaysian Public Sector. The National Conference for Postgraduate Research, University Malaysia Pahang, 135-141.

Sajari, A., Haron, H., \& Ismail, I. (2017). Ethical Climate, Chief Integrity Officer and Level of Ethics and Integrity in Malaysian Public Sector. FGIC 1st Conference on Governance \& Integrity, (April), 297-307.

Taber, K. S. (2017). The Use of Cronbach's Alpha When Developing and Reporting Research Instruments in Science Education. Research in Science Education, 1-24. https://doi.org/10.1007/s11165-016-9602-2

Teacher, L. (2017). There Are Various Types Of Business In Private Sector Company Law Essay. Retrieved August 29, 2017, from https://www.lawteacher.net/free-lawessays/company-law/there-are-various-types-of-business-in-private-sector-company-law-essay.php?cref=1 